\title{
Troponin elevation after black widow spider envenomation
}

\author{
Sean P. Bush, MD*; J. Veeran Davy, $\mathrm{MD}^{\dagger}$ \\ ABSTRACT
}

Black widow spider envenomation generally results in selflimiting pain that can be treated in the emergency department (ED) with analgesics and benzodiazepines, usually with no further intervention. Occasionally, a patient has to be admitted or treated with antivenom for refractory pain or a venom-induced complication. We present the case of an 84year-old man who presented to our ED with chest pain and dyspnea after being bitten on the foot by a western black widow spider (Lactrodectus hesperus). His initial cardiac troponin I (cTnl) was elevated at $0.07 \mathrm{ng} / \mathrm{ml}$ and continued to rise to a peak of $0.17 \mathrm{ng} / \mathrm{ml}$. He also had rhabdomyolysis, another uncommon complication of black widow envenomation. An elevated cTnl generally signifies myocardial injury and is rarely seen after black widow envenomation. We discuss the possible etiologies for an elevated cardiac biomarker, in this context, and review potentially serious complications of widow spider envenomation presenting with chest symptoms and an elevated cardiac biomarker.

\section{RÉSUMÉ}

L'envenimement par piqûre de veuve noire entraîne généralement une douleur qui tend à disparaître spontanément et qui peut se traiter au service des urgences (SU) par des analgésiques et des benzodiazépines, habituellement sans autre intervention. II arrive toutefois que des patients soient hospitalisés ou soient traités par des antivenins pour des douleurs rebelles ou pour des complications causées par le venin. Sera exposé ici le cas d'un homme de 84 ans qui a consulté au SU pour des douleurs thoraciques et de la dyspnée après une piqûre de veuve noire (Lactrodectus hesperus) au pied. Le taux de troponine I cardiaque (t. Ic) à l'arrivée s'élevait à $0,07 \mathrm{ng} / \mathrm{ml}$ et a continué d'augmenter pour atteindre un pic de $0,17 \mathrm{ng} / \mathrm{ml}$. Le patient a également souffert de rhabdomyolyse, une autre complication peu fréquente de l'envenimement par piqûre de veuve noire. Une élévation du taux de $t$. Ic signe généralement une lésion myocardique, et le phénomène s'observe rarement à la suite d'un envenimement par piqûre de veuve noire. II sera question ici des causes possibles de l'élévation du taux de biomarqueur cardiaque dans le contexte, ainsi que des complications potentiellement graves de l'envenimement par piqûre de veuve noire, qui produit des symptômes de type thoracique et une élévation du taux de biomarqueur cardiaque.

Keywords: venom, envenomation, envenoming, widow, spider, bite, latrodectus, mactans, hesperus

\section{INTRODUCTION}

The widow spiders (Latrodectus species) encompass 32 species worldwide, of which the most well known in North America are 3 species of black widows. Envenomation by a black widow usually results in a self-limiting syndrome of severe, cramping muscular pain or spasm, diaphoresis, hypertension, vomiting, and headache. ${ }^{1}$ These symptoms can be treated in the emergency department (ED) with analgesics and benzodiazepines, often with no further intervention. Patients can then be discharged home with oral analgesics as necessary. Occasionally, a patient requires admission or antivenom for refractory pain or venominduced complication.

It is extraordinarily rare for envenomation by a black widow spider to result in a life-threatening condition. One such condition is myocardial injury due to infarction or inflammation. In order to identify patients with myocardial injury associated with black widow envenomation, one must remember to evaluate for it, because some cases may be serious enough to require antivenom and could even be fatal. We present and discuss the case of a patient with elevated cardiac troponin I (cTnI) after a black widow spider bite.

From the *Department of Emergency Medicine, Brody School of Medicine, East Carolina University, Greenville, NC; and tDepartment of Emergency Medicine, School of Medicine, Loma Linda University, Loma Linda, CA.

Correspondence to: Dr. Sean Bush, Department of Emergency Medicine, Brody School of Medicine, East Carolina University, 3 ED 342 , Vidant Medical Center, 600 Moye Blvd., Greenville, NC 27834; Email: seanbushmd@gmail.com 


\section{CASE REPORT}

An 84-year-old man with a past medical history of stroke and smoking presented to the ED with left leg pain 3 hours after being bitten on the left foot by what he and his son convincingly described as a black widow spider (Latrodectus hesperus). He encountered the spider while putting on his shoes in the garage.

His initial vital signs were temperature $36.5^{\circ} \mathrm{C}\left(97.7^{\circ} \mathrm{F}\right)$, heart rate 66 beats per minute, respiratory rate 16 per minute, blood pressure $192 / 64 \mathrm{~mm} \mathrm{Hg}$, and pulse oximetry $98 \%$ on room air. His physical exam was unremarkable, except for a $3-\mathrm{cm}$ area of erythema on the dorsum of his left foot that was mildly tender to palpation.

The pain was isolated to his left leg, and he was treated with an intravenous (IV) opioid analgesics. As a result of his improved condition with parenteral analgesia alone, no further ED workup was performed, and he was sent home with a prescription for an oral opioid. The following day, he returned to the same ED complaining of cramping pain in both of his legs, ascending to his abdomen and chest, and associated with nausea and dyspnea at rest.

Owing to his chest pain, an electrocardiogram (ECG) and comprehensive laboratory investigations, including cardiac biomarkers, were obtained. The ECG showed a rate of 65 beats per minute without ST segment or $\mathrm{T}$-wave evidence of ischemia (Figure 1). The initial labs were total creatine kinase (CK) 373 IU/L, CK-MB $4 \mathrm{IU} / \mathrm{L}$, and $\mathrm{cTnI} 0.07 \mathrm{ng} / \mathrm{ml}$. A cTnI greater than $0.04 \mathrm{ng} / \mathrm{ml}$ at the involved hospital is considered elevated. The blood urea nitrogen (BUN) was $29 \mathrm{~g} / \mathrm{dl}$, and the creatinine was $1.1 \mathrm{mg} / \mathrm{dl}(84.88 \mu \mathrm{mol} / \mathrm{L}$ SI units). Repeat cardiac biomarkers obtained in the ED 5.5 hours later included CK total $735 \mathrm{IU} / \mathrm{L}$, CK-MB 7.9 IU/L, and cTnI $0.13 \mathrm{ng} / \mathrm{ml}$. A chest $\mathrm{x}$-ray was unremarkable. The patient was treated with IV opioids. Because of the chest pain, he was also given aspirin $325 \mathrm{mg}$ and had 1-in. of nitroglycerin paste applied to his chest. His chest pain subsequently improved. Due to supply limitations, antivenin was not available, and the hospital did not have the catheterization lab available to evaluate for coronary artery disease. The patient was admitted to the cardiology service.

Repeat investigations over the next day showed continued rise in cTnI from $0.16 \mathrm{ng} / \mathrm{ml}$ to $0.17 \mathrm{ng} / \mathrm{ml}$ and then to $0.15 \mathrm{ng} / \mathrm{ml}$ on the third day of admission. The patient's total CK increased to a maximum of 1,409 IU/L, and his urinalysis showed large blood on dipstick without red blood cells on microscopy. A transthoracic echocardiogram was performed and showed an ejection fraction of $60 \%$, moderate pulmonary hypertension, and trivial pericardial effusion without evidence of pericarditis. He was discharged home after 4 days with instructions to take an aspirin daily and without further cardiac interventions.

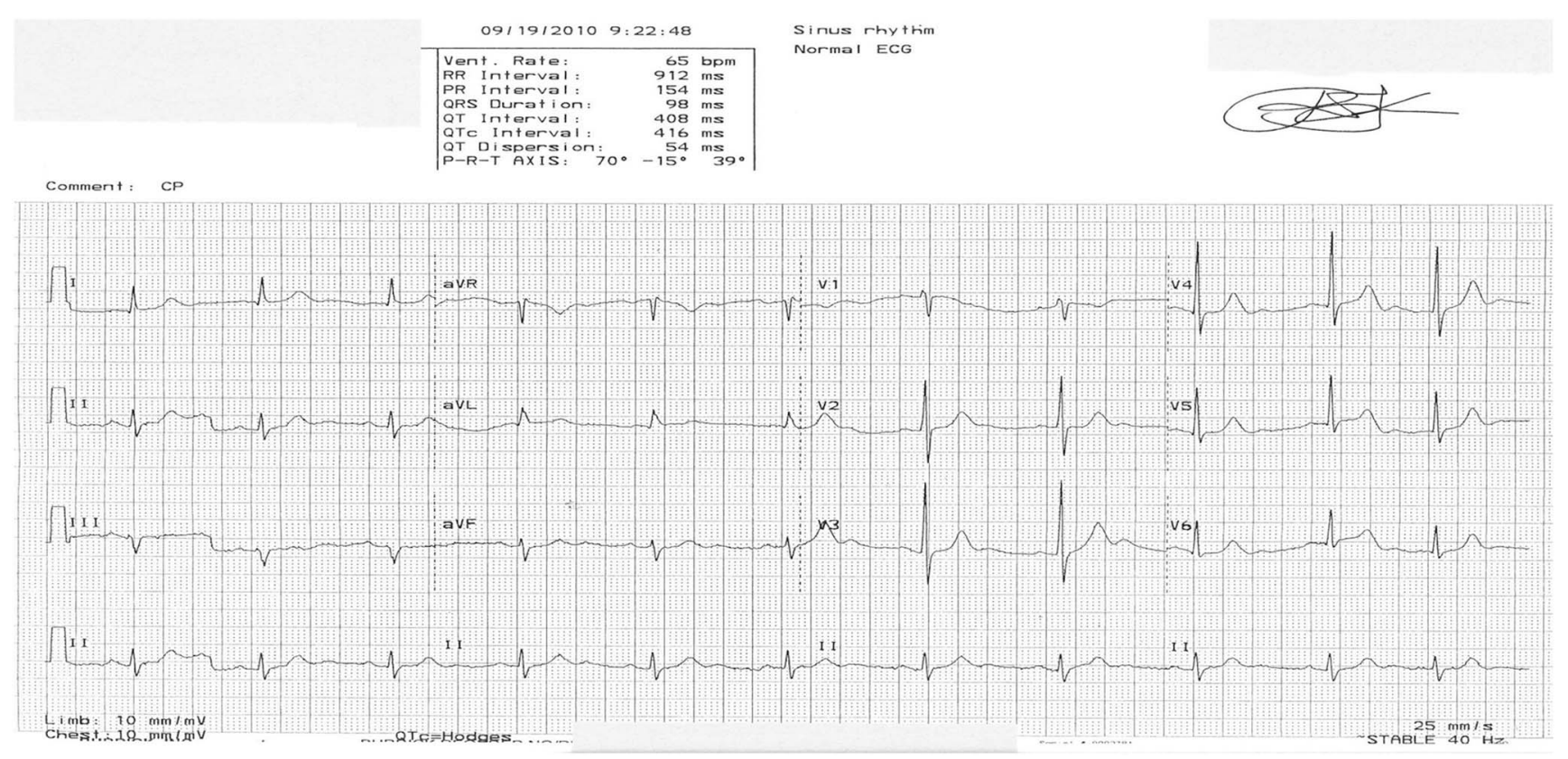

Figure 1. Initial electrocardiogram (ECG) with no ST segment or T-wave findings suggestive of ischemia. 


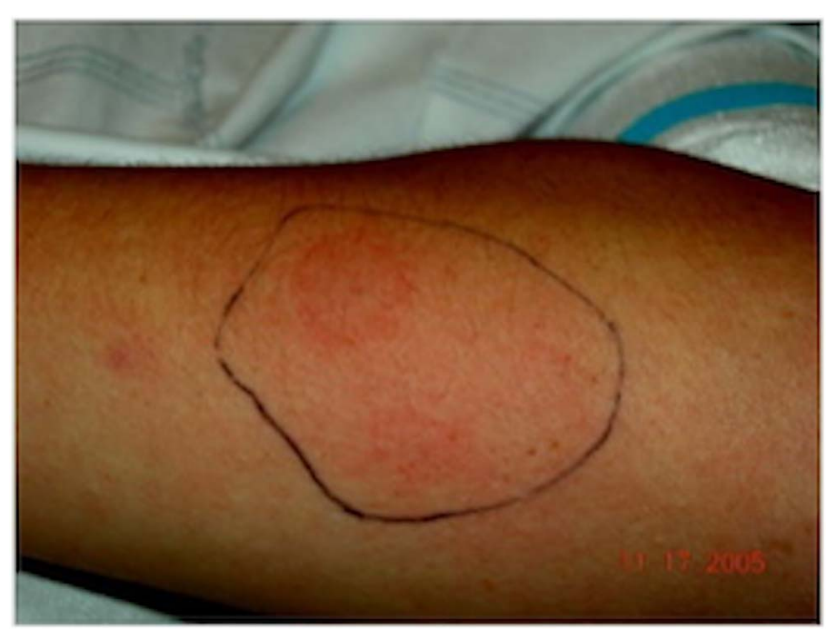

Figure 2. "Target lesion" characteristic of black widow spider envenomation.

\section{DISCUSSION}

Latrodectus hesperus, commonly referred to as the western black widow spider, is found in abundance in the southwestern United States, and its range extends to southern British Columbia, southern Saskatchewan, and Alberta. ${ }^{2}$ Other species of the genus Latrodectus are found throughout the world, including southern regions of Canada, where the weather is more temperate. More than 50,000 black widow spider bites have been reported to poison centres in the United States during the past 25 years. ${ }^{3}$ Bites typically occur when the spider defends itself from being accidentally crushed. ${ }^{4}$ Symptoms usually begin 30 minutes up to 8 hours after envenomation. The local reaction is usually minimal, manifested by a small puncture wound or papule with surrounding erythema or induration, sometimes manifesting as a characteristic target lesion (Figure 2). ${ }^{4}$ Systemic symptoms can occur, including severe, cramping muscular pain or spasm, diaphoresis, hypertension, vomiting, and headache. ${ }^{1}$

In patients who develop chest pain, shortness of breath, or palpitations after a black widow spider bite, the possibility of myocardial ischemia or infarction should be considered. In the patient we present, the combination of hypertension compounded by the widow spider envenomation may have contributed to increased myocardial workload. The muscle cramping associated with widow spider envenomation may include myocardium or the musculature in the coronary arterial wall. Ischemia or non-ST elevation myocardial infarction should be included in the differential diagnosis when a patient presents like ours. However, other serious conditions may present similarly after a black widow spider envenomation, including as acute myocarditis. ${ }^{5}$ Although myocarditis is seen after scorpion or cobra envenomations with relative frequency, it is uncommonly observed after a black widow spider bite. ${ }^{5}$ To our knowledge, only nine cases of myocarditis after black widow envenomation have been reported in the literature..$^{6-14}$ The age distribution of the reported cases ranges from 15 to 65 years old with both males and females affected. Of the nine reported cases, eight occurred in Italy, Morocco, Turkey, or Greece, and one occurred in North America. Only one of those patients died, a 19-year-old woman in Greece.

Our report is limited by the fact that the etiology of our patient's troponin leak is not definitively known. The cTnI is a molecule that is part of the troponin complex that regulates the contractile process of cardiac muscle cells. It is believed to be present in cardiac muscle only, making it a very specific marker of cardiac muscle injury. ${ }^{5}$ The cTnI can detect even minor degrees of myocardial necrosis at the myofibril level. ${ }^{15}$ An increased level of $\mathrm{c} T \mathrm{TI}$ is detectable in the peripheral circulation when the clearance capacity of the cardiac lymphatics is exceeded. ${ }^{16}$ Myocarditis leads to myocardial necrosis secondary to inflammatory cell infiltrates and cytokine activation. 5 Thus, a sensitive and specific marker of myocardial injury from myocarditis is elevated cTnI.

The cTnI elevation, chest pain, and shortness of breath seen in our patient may have been the result of myocarditis. The exact mechanism of myocarditis after black widow spider envenomation is not known. The major component of black widow spider venom, $\alpha$-latrotoxin, is a potent neurotoxin that causes the symptoms associated with envenomation through catecholamine release at adrenergic nerve endings and depletion of acetylcholine at motor nerve endings. Although the nervous system is its primary target, $\propto$-latrotoxin also affects organs, such as the heart and lungs. A catecholamine surge, direct toxicity, and hypersensitivity reaction are all possible mechanisms for $\propto$-latrotoxin that lead to myocarditis. ${ }^{4,6,8,10-12,14}$

Another possible etiology of the c $T n I$ elevation seen in our patient is from rhabdomyolysis, another uncommon complication of black widow spider envenomation. The literature suggests that $\mathrm{cTnI}$ can be elevated in patients who also have an elevated total CK in a range consistent with rhabdomyolysis (CK greater than 1,000 IU/L, which 
is four times the upper limit of normal), as seen in our patient. ${ }^{16-18}$ However, studies show that the correlation between the severity of rhabdomyolysis and the degree of cTnI elevation is poor, ${ }^{16-18}$ and the etiology of how rhabdomyolysis causes cTnI elevation remains unknown. One possible mechanism is micro-injury to the myocardium from free radicals, circulating cytokines, cardiotoxicity due to ion fluxes and high acidemia, hypotension and hypoperfusion, and myocardial stretch due to aggressive fluid resuscitation. ${ }^{16}$

Finally, another possible explanation for the cTnI elevation seen in our patient could be the way the laboratory measures this biomarker. Troponin assays are immunoassays, and cross-reactions may occur with all antibody assays. Troponin I exists in three isoforms: slow skeletal, fast skeletal, and cardiac muscle specific (cTnI). ${ }^{16}$ It is the cardiac muscle specific isoform that is measured when a cTnI is obtained. In patients with rhabdomyolysis, and thus in whom skeletal forms of troponin I are elevated, the altered background signal-to-noise ratio may result in falsely elevated cTnI. ${ }^{17}$ The frequency and degree to which this happens are not known.

It has been noted previously that the ECG may be normal in patients with black-widow-associated myocardial injury, as was also the case in our patient. ${ }^{9}$ Serial cardiac biomarker measurement may be necessary to detect myocardial injury, because it can take some $8-12$ hours for the cTnI to rise. ${ }^{5}$

It is noteworthy that of the nine published cases of myocarditis after black widow spider envenomation, only one (the North American case) was given antivenom. The reasons for this are unclear; some authors explicitly noted that this was due to the lack of availability, whereas others provided no explanation. The case in North America had prompt normalization of the vital signs and resolution of the diaphoresis, fasciculations, and pain after antivenom administration. ${ }^{11}$ Antivenom is a horse serum-derived product containing IgG antibodies. It is indicated for symptoms refractory to opioids and benzodiazepines or for lifethreatening conditions, such as uncontrolled hypertensive emergencies or irreversible organ injury (including myocarditis). Black widow spider antivenin (Merck) is inexpensive at USD 33.25 per vial, and one vial can result in dramatic relief-enough to prevent hospitalization. However, many clinicians are reluctant to administer because of concerns of potential anaphylaxis and serum sickness. Fatal respiratory arrest with severe anaphylactic bronchospasm after antivenom administration has been reported. A recently developed $\mathrm{F}(\mathrm{ab}) 2$ immunoglobulin product, now in phase three clinical trials, is a theoretically safer alternative to the antivenom currently available. ${ }^{19-22}$

\section{CONCLUSION}

As our case illustrates, in a patient who presents with chest pain or shortness of breath after a black widow spider bite, myocarditis or cardiac ischemia should be considered in the differential diagnosis and investigated. In severe cases, antivenom administration may be indicated.

Competing interests: None declared.

\section{REFERENCES}

1. Timms P, Gibbons R. Latrodectism-effects of the black widow spider bite. West 7 Med 1986;144(3):315-7.

2. Klinkenberg B (ed.) E-Fauna BC: Electronic atlas of the fauna of British Columbia. Lab for advanced spatial analysis. Department of Geography, University of British Columbia, Vancouver, 2012. Available at: http://ibis.geog.ubc.ca/ biodiversity/efauna/ (accessed 22 June 2013).

3. Bronstein A, Spyker D, Cantilena L, et al. 2011 Annual Report of the American Association of Poison Control Centers' National Poison Data System (NPDS): 29th annual report. Clin Toxicol 2012;50(10):911-1164.

4. Boyer LV, Binford GJ, Degan JA. Spider bites. In Auerbach PS, ed.: Wilderness medicine, 6th ed. Philadelphia: Elsevier; 2011: 993-5.

5. Liu P, Baughman K. Myocarditis. In Bonow RO, Mann DL, Zipes DP, Libby P, eds.: Braunwald's heart disease: a textbook of cardiovascular medicine, 9th ed. Philadelphia: Elsevier; 2011:1102-5, 1595-1610, 1636.

6. Dendane T, Abidi K, Madani N, et al. Reversible myocarditis after black widow spider envenomation. Case Rep Med 2012;1-4, doi:10.1155/2012/794540.

7. Erdur B, Turkcuer I, Bukiram A, et al. Uncommon cardiovascular manifestations after Latrodectus bite. Am 7 Emerg Med 2007;25(2):232-5.

8. Golcuk Y, Velibey Y, Gonullu H, et al. Acute toxic fulminant myocarditis after a black widow spider envenomation: case report and literature review. Clin Toxicol 2013;51(3):191-2.

9. Kara H, Ak A, Bayir A, et al. Reversible myocarditis after spider bite. BM7 Case Rep 2013, doi:10.1136/bcr-2013008957.

10. Kose A, Bozkurt S, Zengmol M, et al. Presumptive Latrodectus bite with ileus and myocardial involvement. Wilderness Environ Med 2010;21(3):271-2.

11. Levine M, Canning J, Chase R, et al. Cardiomyopathy following Latrodectus envenomation. West 7 Emerg Med 2010;11(5):521-3. 
12. Pneumatikos I, Galiatsou E, Goe D, et al. Acute fatal toxic myocarditis after black widow spider envenomation. Ann Emerg Med 2003;41(1):158.

13. Puligano G, Del Sindaco D, Giovannini M, et al. Myocardial damage after spider bite (Latrodectus tredecimguttatus) in a 16-year-old patient. G Ital Cardiol 1998;28(10): 1149-53.

14. Sari I, Zengin S, Davutoglu V, et al. Myocarditis after black widow spider envenomation. Am 7 Emerg Med 2008; 26(5):630.e1-e3.

15. Khan I, Tun A, Wattanasauwan N, et al. Elevation of serum cardiac troponin I in noncardiac and cardiac diseases other than acute coronary syndromes. Am 7 Emerg Med 1999; 17(3):225-9.

16. Punukollu G, Gowda R, Khan I, et al. Elevated serum cardiac troponin I in rhabdomyolysis. Int 7 Cardiol 2004; 96(1):35-40.
17. Li S, Zapata J, Tillem E.. The prevalence of false-positive cardiac troponin I in ED patients with rhabdomyolysis. $\mathrm{Am}$ 7 Emerg Med 2005;23(7):860-3.

18. Viallon A, Marjollet O, Berger C, et al. Troponin I values during rhabdomyolysis in elderly patients admitted to the emergency department. Presse Med 2006;35(11):1632-8.

19. Bush S. Why no antivenom? Ann Emerg Med 2003;42(3): 431-2.

20. Cohen J, Bush S. Case report: compartment syndrome after a suspected black widow spider bite. Ann Emerg Med 2005;45(4):414-6.

21. Murphy C, Hong J, Beuhler M. Anaphylaxis with Latrodectus antivenin resulting in cardiac arrest. 7 Med Toxicol 2011; 7(4):317-21.

22. Nordt S, Clark R, Lee A, et al. Examination of adverse events following black widow antivenom use in California. Clin Toxicol 2012;50(1):70-3. 